\title{
Influence of Mirtazapine on Salivary Cortisol in Depressed Patients
}

\author{
G. Laakmanna J.Hennig ${ }^{\text {b T. Baghaia }}$ C. Schülea \\ Departments of aPsychiatry, University of Munich, Munich, and ' ${ }^{\text {P }}$ sychology, University of Giessen, \\ Giessen, Germany
}

\section{Key Words}

Mirtazapine - Saliva - Cortisol - Depressive disorder . Treatment response

\begin{abstract}
Unlike other antidepressants, mirtazapine does not inhibit the reuptake of norepinephrine or serotonin but acts as an antagonist at presynaptic $\alpha_{2}$-receptors, at postsynaptic 5-HT2 and 5-HT3 receptors, and at histaminergic $\mathrm{H} 1$ receptors. Furthermore, mirtazapine has been shown to acutely inhibit cortisol secretion in healthy subjects. In the present study, the impact of mirtazapine treatment on salivary cortisol secretion was investigated in 12 patients ( 4 men, 8 women) suffering from major depression according to DSM-IV criteria. Patients were treated with mirtazapine for 3 weeks, receiving $15 \mathrm{mg}$ mirtazapine on day $0,30 \mathrm{mg}$ on day 1 and $45 \mathrm{mg}$ per day from day 2 up to the end of the study (day 21). Response to mirtazapine treatment was defined by a reduction of at least $50 \%$ in the Hamilton Rating Scale for Depression after 3 weeks of therapy. Salivary cortisol concentrations were measured before treatment (day -1 ), at the beginning of treatment (day 0), after 1 week (day 7) and after 3 weeks (day 21) of treatment with mirtazapine. Saliva samples were collected hourly from 08.00 until $20.00 \mathrm{~h}$. The area under the curve values served as parameter for the salivary cortisol secretion. Following analysis of variance with a repeated measures design, tests with contrasts revealed a significant reduction of cortisol concen-
\end{abstract}

trations already after 1 day of mirtazapine treatment that was comparable in responders and nonresponders. In addition to new pharmacological approaches such as $\mathrm{CRH} 1$ receptor antagonists, mirtazapine therefore appears to be an effective strategy to decrease hypercortisolism and restore HPA system dysregulation in depression. However, the importance of the acute inhibitory effects of mirtazapine on cortisol secretion for its antidepressant efficacy has to be further clarified.

Copyright $\odot$ 2003S. Karger AG, Basel

\section{Introduction}

The neuroendocrine challenge paradigm is based on the involvement of monoamine pathways in the control of anterior pituitary hormone secretion [1]. Psychotropic drugs with different effects on the central neurotransmitter system have distinct effects on the anterior pituitary hormone secretion and can be characterized by certain pharmacoendocrinological profiles (table 1). Antidepressants which primarily act via noradrenaline (NA) reuptake inhibition (e.g. desimipramine, DMI) stimulate growth hormone $(\mathrm{GH})$ secretion [23], whereas serotonin (5-HT) reuptake-inhibiting antidepressants (e.g. indalpine, chlorimipramine) are characterized by prolactin (PRL) stimulation [4]. Cortisol (COR) secretion can acutely be increased by antidepressants with both NA or 5-HT reuptake inhibition; the stimulatory effects of antidepressants on COR secretion are mediated via stimulation of the ACTH output of the pituitary gland [4].

\begin{tabular}{ll}
\hline KARGER & ( ) 2003 S. Karger AG, Basel \\
Fax +4161306 1234 & \\
$\begin{array}{l}\text { E-Mail karger@karger.ch } \\
\text { www.karger.com }\end{array}$ & $\begin{array}{l}\text { Accessible online at: } \\
\text { www.karger.com/nps }\end{array}$
\end{tabular}

Cornelius Schüle, MD

Department of Psychiatry, Ludwig Maximilian University

Nussbaumstrasse 7, D-80336 Munich (Germany)

Tel. +495160 5810, Fax +4951605391

E-Mail Cornelius.Schuele@psy.med.uni-muenchen.de 
Table 1. The influence of acute administration of antidepressant agents on neurotransmitter reuptake in vitro ( $\mathrm{IC}_{50}$ values) and $\mathrm{GH}, \mathrm{PRL}$ and $\mathrm{COR}$ secretion in man

\begin{tabular}{ccllrllll}
\hline NA & 5-HT & DA & & & & GH & PRL & COR \\
\hline 0.9 & 210 & V & DMI & $25 \mathrm{mg}$ & i.v. & +++ & ++ & +++ \\
& & & DMI & $100 \mathrm{mg}$ & p.o. & +++ & + & +++ \\
1.1 & $\mathrm{~V}$ & $\mathrm{~V}$ & D-Oxa & $75 \mathrm{mg}$ & i.v. & +++ & 0 & +++ \\
$\mathrm{V}$ & $\mathrm{V}$ & $\mathrm{V}$ & L-Oxa & $75 \mathrm{mg}$ & p.o. & 0 & 0 & 0 \\
6.6 & 830 & 48 & NF & $200 \mathrm{mg}$ & p.o. & ++ & - & n.a. \\
24 & 1.5 & $\mathrm{~V}$ & CI & $25 \mathrm{mg}$ & i.v. & ++ & +++ & +++ \\
& & & CI & $100 \mathrm{mg}$ & p.o. & ++ & + & + \\
$\mathrm{V}$ & 2.4 & $\mathrm{~V}$ & IND & $25 \mathrm{mg}$ & i.v. & 0 & ++ & +++ \\
\hline
\end{tabular}

$\mathrm{V}=\mathrm{IC}_{50}>1,000 \mathrm{n} M ; \mathrm{NA}=$ noradrenaline $;$ 5- $\mathrm{HT}=$ serotonin $; \mathrm{DA}=$ dopamine $; \mathrm{DMI}=$ desipramine; Oxa = oxaprotiline; $\mathrm{NF}=$ nomifensine; $\mathrm{CI}=$ chlorimipramine; IND = indalpine; i.v. $=$ intravenous; n.a. $=$ not available; p.o. $=$ per os; $+++=$ strong stimulation; $++=$ moderate stimulation; $+=$ slight stimulation; $-=$ inhibition; $0=$ no significant effect . Table modified from Hyttel [2].
Unlike other antidepressants, mirtazapine does not inhibit the reuptake of norepinephrine or serotonin but acts as an antagonist at presynaptic $\alpha_{2}$-receptors and at postsynaptic 5-HT2 and 5-HT3 receptors [5]. Mirtazapine enhances NA release by blocking $\alpha_{2}$-autoreceptors [5, 6]. Serotonergic neurotransmission is also increased by mirtazapine, especially in the hippocampus, via two synergistic mechanisms: an increase of 5-HT cell firing and a blockade of $\alpha_{2}$-adrenergic heteroreceptors at the 5-HT nerve terminals [7-9]. In addition, mirtazapine is an antihistaminergic agent with a high affinity for histamine $\mathrm{H} 1$ receptors [10] and has only few anticholinergic side effects. Average peak plasma concentrations are achieved $2 \mathrm{~h}$ after oral dosing and the elimination half-life is in the range of 20-40 $\mathrm{h}$ [11].

In former studies of our research group mirtazapine was shown to acutely inhibit COR and ACTH secretion in healthy subjects, whereas GH and PRL secretion patterns remained unchanged $[12,13]$. The endocrinological effects of mirtazapine observed in healthy volunteers strongly differ from those seen in reuptake-inhibiting antidepressants and may reflect the unique mechanism of action of mirtazapine. Whereas reuptake inhibitors acutely stimulate the COR release of the adrenal gland in healthy volunteers [4, 14-16], mirtazapine obviously acts as an acute cortisol inhibitor in normal controls.

The COR inhibition after first-time administration of mirtazapine in normal volunteers is of special interest in the light of the hypercortisolism demonstrated in depressive patients. Preclinical and clinical studies suggest that hypothalamic-pituitary-adrenal (HPA) system dysregulation is related to the occurrence of depression [17]. Significantly elevated urinary free COR excretion or 24-hour
COR blood concentrations have been shown in severely depressed patients [18-23]. Furthermore, COR escape from dexamethasone suppression has been reported during major depression [24-27]. If the combined dexamethasone suppression/CRH stimulation test (DEX/CRH test) is used, the sensitivity in discriminating between depressive patients and healthy controls can be further increased [28]. These findings give reason to ask whether mirtazapine is able to rapidly restore HPA axis dysregulation in depressive disorder by acute reduction of COR secretion patterns.

\section{Methods}

\section{Subjects}

The study was carried out according to the fifth revision of the Declaration of Helsinki [29] and had been approved by an ethics committee. Twelve depressive inpatients ( 4 men, 8 women) gave informed written consent and were included in this study. Inclusion criteria were (a) a major depressive episode according to DSM-IV criteria [30]; (b) a score of at least 18 on the 21-item Hamilton Depression Rating Scale (21-HAMD [31]); (c) no history of substance abuse or dependency; (d) exclusion of neurological or medical disorders, and (e) no psychotropic drugs for at least 5 days prior to the study, except chloralhydrate given in case of patients experiencing difficulties sleeping. Any physical illness was ruled out by a thorough physical and psychiatric examination and routine laboratory test, including electrocardiogram and electroencephalogram. None of the female patients received hormonal contraceptives or hormone replacement therapy. Clinical characteristics are given in table 2 .

\section{Mirtazapine Treatment, Collection of Saliva Samples and} Clinical Ratings

The 12 patients were treated with mirtazapine monotherapy for at least 3 weeks. They received $15 \mathrm{mg}$ mirtazapine at $08.00 \mathrm{~h}$ on day $0 ; 30 \mathrm{mg}$ on day $1(15 \mathrm{mg}$ at $08.00 \mathrm{~h}, 15 \mathrm{mg}$ at $22.00 \mathrm{~h})$, and $45 \mathrm{mg} /$ 
Table 2. Demographic and clinical data of 12 depressed patients treated with mirtazapine

\begin{tabular}{cllllllll}
\hline \multirow{2}{*}{ Patient } & $\begin{array}{l}\text { Sex/age, } \\
\text { years }\end{array}$ & $\begin{array}{l}\text { DSM-IV } \\
\text { diagnosis }\end{array}$ & \multicolumn{2}{l}{ 21-HAMD } & \multirow{2}{*}{ Response } \\
\cline { 4 - 6 } & & & day -1 & day 0 & day 7 & day 21 & \\
\hline 1 & M/25 & 296.23 & 28 & 26 & 10 & 5 & $\mathrm{R}$ \\
2 & $\mathrm{~F} / 60$ & 296.24 & 36 & 36 & 33 & 32 & $\mathrm{NR}$ \\
3 & $\mathrm{~F} / 30$ & 296.33 & 35 & 32 & 22 & 14 & $\mathrm{R}$ \\
4 & $\mathrm{~F} / 41$ & 296.32 & 26 & 27 & 25 & 16 & $\mathrm{NR}$ \\
5 & $\mathrm{~F} / 48$ & 296.32 & 23 & 23 & 13 & 9 & $\mathrm{R}$ \\
6 & $\mathrm{~F} / 34$ & 296.32 & 29 & 28 & 24 & 19 & $\mathrm{NR}$ \\
7 & $\mathrm{~F} / 28$ & 296.23 & 33 & 29 & 23 & 19 & $\mathrm{NR}$ \\
8 & $\mathrm{~F} / 21$ & 296.33 & 28 & 27 & 25 & 27 & $\mathrm{NR}$ \\
9 & $\mathrm{M} / 40$ & 296.32 & 19 & 14 & 7 & 5 & $\mathrm{R}$ \\
10 & $\mathrm{M} / 51$ & 296.32 & 22 & 18 & 10 & 10 & $\mathrm{R}$ \\
11 & $\mathrm{M} / 45$ & 296.32 & 22 & 22 & 10 & 16 & $\mathrm{NR}$ \\
12 & $\mathrm{~F} / 56$ & 296.32 & 20 & 18 & 12 & 10 & $\mathrm{R}$ \\
\hline
\end{tabular}

21-HAMD: Hamilton Depression Rating Scale, 21-items, sum score; day -1: before mirtazapine treatment; day 0: first application of $15 \mathrm{mg}$ mirtazapine; day 7 and day 21: continuation of mirtazapine treatment at a dosage of $45 \mathrm{mg} /$ day; Response $=\geq 50 \%$ reduction in 21-HAMD sum score after 21 days of mirtazapine treatment; $\mathrm{R}=$ responder; $\mathrm{NR}=$ nonresponder. day $(15 \mathrm{mg}$ at $08.00 \mathrm{~h}, 30 \mathrm{mg}$ at $22.00 \mathrm{~h})$ from day 2 up to the end of the study (day 21). Salivary COR concentrations were measured before treatment (day -1 ), at the beginning of treatment (day 0 ), after 1 week (day 7) and after 3 weeks (day 21) of treatment with mirtazapine. On each study day $(-1,0,7,21)$ saliva samples were collected hourly from $08.00 \mathrm{~h}$ up to $20.00 \mathrm{~h}$. Severity of depression was assessed on the days of saliva sampling using the 21-HAMD. Response to mirtazapine treatment was defined by a reduction of at least $50 \%$ in the 21-HAMD sum score after 3 weeks of therapy. All raters were experienced psychiatrists and blind to hormonal measurements.

\section{Measurement of Salivary COR}

Saliva was obtained using special tubes containing a small cotton wool swab (Salivette, Sarstedt, Rommelsdorf, Germany). Patients were asked to take the tube, open it and put the cotton swab into the mouth. After 3 min patients had to take the swab out and put it back into the tube.

A special radioimmunoassay ('Magic COR', Ciba Corning, Fernwald, Germany) was used to determine COR concentrations in the salivary samples. As previously described by Kirschbaum et al. [32], this assay was slightly modified using diluted standards (1:10), a prolonged time of incubation $(3.5 \mathrm{~h})$, and a different amount of tracer as well as antibody to obtain a concentration range typical for saliva COR, which (representing the free fraction of the hormone) is about 1:10 lower in saliva than in peripheral blood.

\section{Statistical Evaluation}

The area under the curve (AUC) values between $\mathrm{t}=0 \mathrm{~h}$ and $\mathrm{t}=12$ $\mathrm{h}$ served as parameter for the salivary COR secretion. Correlations between baseline AUC values (day -1) and both age and severity of illness at baseline (as measured by the 21-HAMD sum score at day $-1)$ were tested for significance using Pearson's correlation coefficient. To compare the salivary COR secretion before and during mir- tazapine treatment (day -1, 0, 7, and 21) and to compare the change in salivary COR levels during mirtazapine therapy between responders and nonresponders, a two-way ANOVA with a repeated measures design was carried out. 'Treatment', i.e. the salivary COR AUC values before and during mirtazapine treatment (day $-1,0,7$, and 21), was the within-subjects factor, whereas 'group' served as betweensubjects factor (response versus nonresponse). As a follow-up procedure to make pairwise comparisons between the AUC values during mirtazapine treatment (day $0,7,21)$ and the baseline AUC values $($ day -1$)$, respectively, tests with contrasts were performed. As a nominal level of significance, $\alpha=0.05$ was accepted.

\section{Results}

Six patients responded to 3-week mirtazapine treatment, whereas the other 6 patients were nonresponders. At baseline (week 0), the 21-HAMD sum scores were comparable between responders and nonresponders $(t=$ 1.410; d.f. $=10 ; \mathrm{p}=$ n.s.). During mirtazapine treatment, responders showed a clear-cut amelioration of depressive symptoms, whereas nonresponders remained depressed. Mean 21-HAMD sum scores were (mean \pm SD): responders day $-1: 24.50 \pm 6.02$; day $0: 21.83 \pm 6.52$; day 7: $12.33 \pm 5.16$; day $21: 8.83 \pm 3.43$; nonresponders day $-1: 29.00 \pm 4.98$; day 0: $28.17 \pm 4.54$; day 7: $23.33 \pm$ 7.45; day 21: $21.50 \pm 6.53$. Male and female patients were comparable in baseline COR AUC values $(t=1.175$; d.f. $=10 ; p=n . s$.). However, there was a significant positive correlation between age and salivary COR AUC val- 

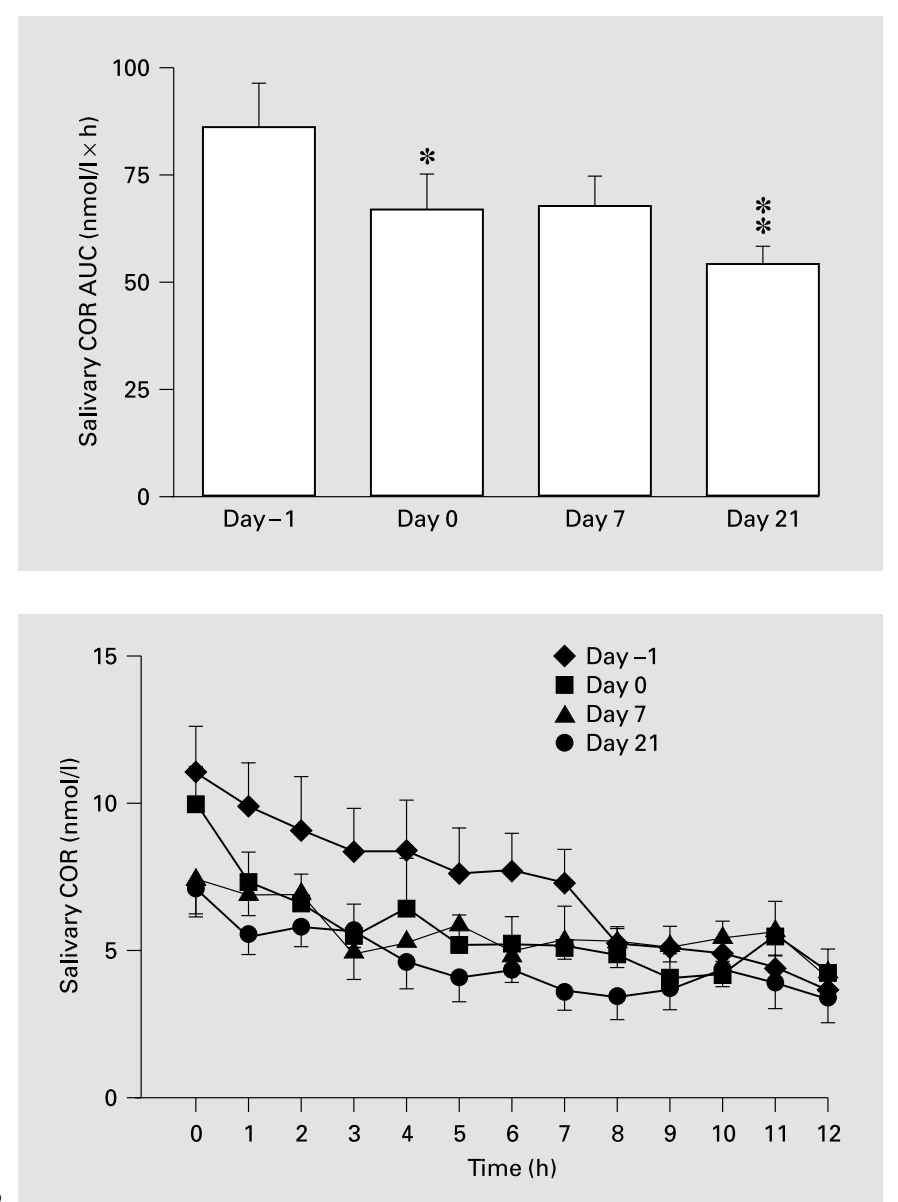

Fig. 1. Means \pm SEM of salivary COR AUC values in depressed patients $(n=12)$ on day -1 (before mirtazapine treatment), day 0 (first application of $15 \mathrm{mg}$ mirtazapine), day 7 and day 21 (continuation of mirtazapine treatment at a dosage of $45 \mathrm{mg} /$ day). ${ }^{*} \mathrm{p}<0.05$; $* * \mathrm{p}<0.01$. For further statistics please see Results.

Fig. 2. Means \pm SEM of salivary COR concentrations in depressed patients $(n=12)$ on day -1 (before mirtazapine treatment), day 0 (first application of $15 \mathrm{mg}$ mirtazapine), day 7 and day 21 (continuation of mirtazapine treatment at a dosage of $45 \mathrm{mg} /$ day). Mean value graph represents the salivary COR concentrations from $08.00(\mathrm{t}=$ $0 \mathrm{~h})$ to $20.00 \mathrm{~h}(\mathrm{t}=12 \mathrm{~h})$.

ues on day $-1(\mathrm{r}=0.693 ; \mathrm{p}=0.013)$. Thus 'age' was considered a covariate in the repeated measures ANOVA in order to eliminate its influence on the possible effects of the factors 'treatment' and 'group'.

Before mirtazapine treatment, the mean salivary COR AUC value was $85.78 \pm 37.16 \mathrm{nmol} / 1 \times$ hour. However, there was a pronounced reduction of COR AUC values after the first administration of mirtazapine (day 0) already, which lasted up to the end of the treatment period (day 0: $66.77 \pm 30.24$, day 7: $68.10 \pm 22.99$, day 21: $53.95 \pm 14.79 \mathrm{nmol} / 1 \times$ hour; fig. 1,2$)$. Repeated mea- sures ANOVA (Wilks' multivariate tests of significance) revealed a significant 'treatment' effect $(\mathrm{F}=4.721$; d.f. $=$ 3,7 ; sign. of $F=0.042$ ), suggesting an significant inhibitory impact of mirtazapine on cortisol secretion. However, there was no significant 'group' effect (responders vs. nonresponders: $F=0.090$; d.f. $=1$, 9; sign. of $F=0.771$ ) nor was there any significant 'treatment by group' effect $(\mathrm{F}=$ 0.377 ; d.f. $=3,7 ; p=0.773$ ). In other words, the decline in cortisol secretion patterns (salivary COR AUC values) due to mirtazapine therapy was comparable between responders and nonresponders. In the post-hoc tests with contrasts, there was a significant decrease of COR AUC values already after the first day of mirtazapine treatment $(p=0.05)$. COR inhibition became also obvious on day 7 ; however, compared to baseline (day -1$)$ the difference was not statistically significant $(\mathrm{p}=0.07)$. On day 21 , a highly significant reduction of COR secretion in comparison to day -1 could be demonstrated $(p=0.001)$.

\section{Discussion}

We found a positive correlation between age and COR secretion (salivary COR AUC values) at baseline (day -1). This result is in line with investigators who have found age to be positively associated with COR secretion during depression [33, 34], especially in women [35] and severely depressed patients [36].

The main finding of our investigation is that mirtazapine significantly decreases COR secretion in depressive patients. Apparently, this COR inhibition is acute and begins after the first administration of mirtazapine, since on day 0 (application of $15 \mathrm{mg}$ mirtazapine at $08.00 \mathrm{~h}$ ) the mean COR concentrations were already reduced $1 \mathrm{~h}$ after administration of mirtazapine compared to the drug-free condition (fig. 2). During the following 3 weeks of mirtazapine treatment, diurnal COR secretion was further reduced by mirtazapine, reaching a minimum after 3 weeks of therapy. The decline of salivary COR concentrations from morning to evening, already observed before mirtazapine treatment (day -1$)$, can be explained best by the circadian rhythm of COR secretion (maximum of COR concentrations early in the morning followed by a physiological reduction of COR levels).

The acute COR inhibition by mirtazapine, which can be demonstrated both in healthy subjects $[12,13]$ and depressed patients [the present study], can hardly be explained by the $\alpha_{2}$-blocking properties of mirtazapine because yohimbine, an $\alpha_{2}$-blocker, increases the DMIinduced COR stimulation in humans [14]. Given alone, 
COR release from the adrenal gland is not influenced by yohimbine [37]. However, there is evidence from the literature that antagonism of central 5-HT2 and histamine H1 receptors may be responsible for the acute inhibitory effects of mirtazapine on COR secretion.

Different reports have demonstrated that both the synthesis and release of $\mathrm{CRH}$ by hypothalamic tissues in vitro [38, 39] and in vivo [40-42] are stimulated by 5-HT, and that the antiserotonergic drug cyproheptadine inhibits these effects [39]. It seems that 5-HT is one of the physiological factors involved in CRH stimulation at the hypothalamic level [43]. The inhibitory effect of cyproheptadine on ACTH secretion via CRH is thought to be responsible for the positive results observed in some patients with Cushing disease treated with cyproheptadine [44, 45]. Furthermore, it has been shown that activation of 5HT1A, 5-HT2A and 5-HT2C, but not of 5-HT3 receptors results in elevated levels of plasma corticosterone; according to Berendsen et al. [46], serotonergic modulation of $\mathrm{ACTH}$ release via $\mathrm{CRH}$ plays an important role in this context. In the face of the presumed serotonergic modulation of CRH, ACTH and COR secretion, it seems to be likely that the COR inhibition seen after application of mirtazapine is, at least in parts, caused by its 5-HT2A and 5-HT2C receptor-blocking properties.

Besides serotonergic transmission, the neurotransmitter histamine also has to be taken into account. Histamine stimulates the release of ACTH via activation of central postsynaptic $\mathrm{H} 1$ or $\mathrm{H} 2$ receptors; the effect of histamine is indirect and may involve the hypothalamic-regulating factors $\mathrm{CRH}$ and arginine vasopressin [47]. In normal human volunteers, the selective $\mathrm{H} 1$ receptor antagonist meclastine is able to inhibit the ACTH and COR stimulation in the insulin hypoglycemia test, whereas GH and PRL concentrations are unaffected [48]. In rats, antidepressants which display an $\mathrm{H} 1$ antihistaminergic activity (such as imipramine, doxepin, mianserin, desipramine, and amitriptyline) significantly suppress the histamine- induced ACTH release [49]. Regarding these human and animal studies, the H1-blocking effects of mirtazapine may also play a role in the COR inhibition demonstrated in our investigation.

There is evidence that antidepressants with reuptakeinhibiting properties may act in part through gradual normalization of HPA system hyperactivity [17, 50]. Furthermore, in patients who respond clinically to antidepressant therapy but still have a substantially increased COR response in the combined DEX/CRH test at discharge, a higher risk for relapse within the following 6 months has been demonstrated [51]. In contrast to mirtazapine, reuptake-inhibiting antidepressants acutely stimulate COR and ACTH secretion [4, 14-16] and may normalize HPA axis hyperactivity in depressed patients via upregulation of glucocorticoid receptor mRNA levels and enhancement of glucocorticoid receptor function [52]. Apparently, the acute COR inhibition in healthy subjects and depressed patients after administration of mirtazapine is due to a direct pharmacoendocrinological effect of this antidepressant (presumably acute reduction of hypothalamic CRH release by blockade of central 5-HT2 and/ or $\mathrm{H} 1$ receptors), which seems to be different from the gradual normalization of COR and ACTH hypersecretion observed during treatment with reuptake inhibitors such as amitriptyline [50].

Future studies will have to investigate the long-term effects of mirtazapine on COR secretion and its influence on HPA axis activity in depressed patients as measured by the combined DEX/CRH test. Since the COR inhibition was comparable in responders and nonresponders, the importance of the acute inhibitory effects of mirtazapine on COR secretion for its antidepressant efficacy has to be further clarified. In addition to new pharmacological approaches such as CRH1 receptor antagonists [17], mirtazapine may be an effective strategy to restore HPA system dysregulation in depression.

\section{References}

1 Tuomisto J, Mannisto P: Neurotransmitter regulation of anterior pituitary hormones. Pharmacol Rev 1985;37:249-332.

2 Hyttel J: Citalopram - Pharmacological profile of a specific serotonin uptake inhibitor with antidepressant activity. Prog Neuropsychopharmacol Biol Psychiatry 1982;6:277-295.

3 Laakmann G, Schon HW, Wittmann M: Desipramine and growth hormone secretion. Lancet 1981;2:996.
4 Laakmann G: Psychopharmaco-endocrinology and depression research. Monogr Gesamtgeb Psychiatr Psychiatry Ser 1988;46:1-220. In German.

5 De Boer T: The effects of mirtazapine on central noradrenergic and serotonergic neurotransmission. Int Clin Psychopharmacol 1995; 10(suppl 4):19-23.
6 De Boer T, Ruigt GSF, Berendsen HHG: The $\alpha-2$ selective adrenoceptor antagonist Org 3770 (mirtazapine Remeron) enhances noradrenergic and serotonergic transmission. Hum Psychopharmacol 1995;10(suppl 2):107-119.

7 De Boer TH, Nefkens F, Van Helvoirt A, van Delft AM: Differences in modulation of noradrenergic and serotonergic transmission by the $\alpha-2$ adrenoceptor antagonists, mirtazapine, mianserin and idazoxan. J Pharmacol Exp Ther 1996;277:852-860. 
8 Haddjeri N, Blier P, de Montigny C: Effect of the $\alpha-2$ adrenoceptor antagonist mirtazapine on the 5-hydroxytryptamine system in the rat brain. J Pharmacol Exp Ther 1996;277:861871

9 Haddjeri N, Blier P, de Montigny C: Effects of long-term treatment with the $\alpha-2$ adrenoceptor antagonist mirtazapine on 5-HT neurotransmission. Naunyn Schmiedebergs Arch Pharmacol 1997;355:20-29.

10 De Boer TH, Maura G, Raiteri M, de Vos CJ, Wieringa J, Pinder RM: Neurochemical and autonomic pharmacological profiles of the 6 aza-analogue of mianserin, Org 3770 and its enantiomers. Neuropharmacology 1988;27: 399-408.

11 Timmer CJ, Paanakker JE, Vrijmoed-de Vries M: Mirtazapine pharmacokinetics with two dosage regimens and two pharmaceutical formulations. Pharm Res 1997;14:98-102.

12 Laakmann G, Schule C, Baghai T, Waldvogel E: Effects of mirtazapine on growth hormone, prolactin, and cortisol secretion in healthy male subjects. Psychoneuroendocrinology 1999;24:769-784.

13 Schüle C, Baghai T, Goy J, Bidlingmaier M, Strasburger C, Laakmann G: The influence of mirtazapine on anterior pituitary hormone secretion in healthy male subjects. Psychopharmacology (Berl) 2002;163:95-101 .

14 Laakmann G, Wittmann M, Schoen HW, Zygan K, Weiss A, Meissner R, Mueller OA, Stalla GK: Effects of receptor blockers (methysergide, propranolol, phentolamine, yohimbine and prazosin) on desimipramine-induced pituitary hormone stimulation in humans. 3. Hypothalamo-pituitary-adrenocortical axis. Psychoneuroendocrinology 1986;11:475-489.

15 Hennig J, Lange N, Haag A, Rohrmann S, Netter P: Reboxetine in a neuroendocrine challenge paradigm: Evidence for high cortisol responses in healthy subjects scoring high on subclinical depression. Int $\mathbf{J}$ Neuropsychopharmacol 2000;3:193-201.

16 Hennig J, Netter P: Oral application of citalopram $(20 \mathrm{mg})$ and its usefulness for neuroendocrine challenge tests. Int $\mathrm{J}$ Neuropsychopharmacol 2002;5:67-71.

17 Holsboer F: The corticosteroid receptor hypothesis of depression. Neuropsychopharmacology 2000;23:477-501.

18 Gibbons JL, McHugh PR: Plasma cortisol in depressive illness. J Psychiat Res 1962;1:162171.

19 Doig RJ, Mummery RV, Willis MR, Elkes A Plasma cortisol levels in depression. Br J Psychiatry 1966;112:1263-1267.

20 Butler PW, Besser GM: Pituitary-adrenal function in severe depressive illness. Lancet 1968; : 1234-1236.

21 Sachar EJ, Hellman L, Roffwarg HP, Halpern FS, Fukushima DK, Gallagher TF: Disrupted 24-hour patterns of cortisol secretion in psychotic depression. Arch Gen Psychiatry 1973; 28:19-24.

22 Carroll BJ, Curtis GC, Mendels J: Cerebrospinal fluid and plasma free cortisol concentrations in depression. Psychol Med 1976;6:235244.
23 Stokes PE, Stoll PM, Koslow SH, Maas JW, Davis JM, Swann AC, Robins E: Pretreatment DST and hypothalamic-pituitary-adrenocortical function in depressed patients and comparison groups. A multicenter study. Arch Gen Psychiatry 1984;41:257-267.

24 Carroll BJ, Mendels J: Neuroendocrine regulation in affective disorder; in Sachar EJ (ed): Hormones, behavior and psychopathology. New York, Raven Press, 1976.

25 Carroll BJ, Feinberg M, Greden JF, Tarika J, Albala AA, Haskett RF, James NM, Kronfol Z, Lohr N, Steiner M, de Vigne JP, Young E: A specific laboratory test for the diagnosis of melancholia. Standardization, validation, and clinical utility. Arch Gen Psychiatry 1981;38: 15-22.

26 Brown WA, Shuey I: Response to dexamethasone and subtype of depression. Arch Gen Psychiatry 1980;37:747-751.

27 Holsboer F, Bender W, Benkert O, Klein HE, Schmauss M: Diagnostic value of dexamethasone suppression test in depression. Lancet 1980;ii:706.

28 Heuser I, Yassouridis A, Holsboer F: The combined dexamethasone/CRH test: A refined laboratory test for psychiatric disorders. J Psychiatr Res 1994;28:341-356.

29 World Medical Association: World Medical Association Declaration of Helsinki, ethical principles for medical research involving human subjects. Ferney-Voltaire, WMA, 2000. http://www.wma.net/e/policy/17-c_e.html.

30 American Psychiatric Association: Diagnostic and Statistical Manual of Mental Disorders, ed 4 (revised). Washington, American Psychiatric Press, 1994.

31 Hamilton M: A rating scale for depression. J Neurol Neurosurg Psychiatry 1960;23:56-62.

32 Kirschbaum C, Strasburger CJ, Jammers W, Hellhammer DH: Cortisol and behavior: 1. Adaptation of a radioimmunoassay kit for reliable and inexpensive salivary cortisol determination. Pharmacol Biochem Behav 1989;34:747751.

33 Asnis GM, Sachar EJ, Halbreich U, Nathan RS, Novacenko H, Ostrow LC: Cortisol secretion in relation to age in major depression. Psychosom Med 1981;43:235-242.

34 Halbreich U, Asnis GM, Zumoff B, Nathan RS, Shindledecker R: Effect of age and sex on cortisol secretion in depressives and normals. Psychiatry Res 1984;13:221-229.

35 Akil H, Haskett RF, Young EA, Grunhaus L, Kotun J, Weinberg V, Greden J, Watson SJ: Multiple HPA profiles in endogenous depression: Effect of age and sex on cortisol and $\beta$ endorphin. Biol Psychiatry 1993;33:73-85.

36 Jacobs S, Mason J, Kosten T, Brown S, Ostfeld A: Urinary free cortisol excretion in relation to age in acutely stressed persons with depressive symptoms. Psychosom Med 1984;46:213-221.

37 Laakmann G, Dieterle D, Weiss L, Schmauss $\mathrm{M}$ : Therapeutic and neuroendocrine studies using yohimbine and antidepressants in depressed patients and healthy subjects; in Langer SZ (ed): Advances in the Biosciences. Oxford, Pergamon Press, 1982, vol 40, pp 295301 .
38 Buckingham JC, Hodges JR: Hypothalamic receptors influencing the secretion of corticotrophin-releasing hormone in the rat. J Physiol 1979;290:421-431.

39 Jones MT, Birmingham M, Gillham B, Holmes M, Smith T: The effect of cyproheptadine on the release of corticotrophin releasing factor. Clin Endocrinol (Oxf) 1979;10:203-205.

40 Imura H, Nakai Y, Yoshimi T: Effect of 5 hydroxytryptophan (5-HTP) on growth hormone and ACTH release in man. J Clin Endocrinol Metab 1973;36:204-206.

41 Lewis DA, Sherman BM: Serotonergic stimulation of adrenocorticotropin secretion in man. J Clin Endocrinol Metab 1984;58:458-462.

42 Nakanishi S, Inoue A, Kita T, Nakamura M, Chang AC, Cohen SN, Numa S: Nucleotide sequence of cloned cDNA for bovine corticotropin- $\beta$-lipotropin precursor. Nature 1979; 278:423-427.

43 Cavagnini F, Raggi U, Micossi P, Di Landro A, Invitti C: Effect of an antiserotoninergic drug, metergoline, on the ACTH and cortisol response to insulin hypoglycemia and lysinevasopressin in man. J Clin Endocrinol Metab 1976;43:306-312.

44 Krieger DT, Amorosa L, Linick F: Cyproheptadine-induced remission of Cushing's disease. N Engl J Med 1975;293:893-896.

45 Krieger DT, Luria M: Effectiveness of cyproheptadine in decreasing plasma ACTH concentrations in Nelson's syndrome. J Clin Endocrinol Metab 1976;43:1179-1182.

46 Berendsen HH, Kester RC, Peeters BW, Broekkamp CL: Modulation of 5-HT receptor subtype-mediated behaviours by corticosterone. Eur J Pharmacol 1996;308:103-111.

47 Kjaer A, Knigge U, Plotsky PM, Bach FW, Warberg J: Histamine $\mathrm{H} 1$ and $\mathrm{H} 2$ receptor activation stimulates ACTH and $\beta$-endorphin secretion by increasing corticotropin-releasing hormone in the hypophyseal portal blood. Neuroendocrinology 1992;56:851-855.

48 Allolio B, Deuss U, Kaulen D, Winkelmann W: Effect of meclastine, a selective $\mathrm{H} 1$ receptor antagonist, upon ACTH release. Clin Endocrinol (Oxf) 1983; 19:239-245.

49 Reilly MA, Sigg EB: Suppression of histamineinduced adrenocorticotropic hormone release by antihistamines and antidepressants. J Pharmacol Exp Ther 1982;222:583-588.

50 Heuser IJ, Schweiger U, Gotthardt U, Schmider J, Lammers CH, Dettling M, Yassouridis A, Holsboer F: Pituitary-adrenal-system regulation and psychopathology during amitriptyline treatment in elderly depressed patients and normal comparison subjects. Am J Psychiatry 1996;153:93-99.

51 Zobel AW, Yassouridis A, Frieboes RM, Holsboer F: Prediction of medium-term outcome by cortisol response to the combined dexamethasone-CRH test in patients with remitted depression. Am J Psychiatry 1999;156:949951

52 Barden N, Reul JM, Holsboer F: Do antidepressants stabilize mood through actions on the hypothalamic-pituitary-adrenocortical system? Trends Neurosci 1995;18:6-11. 